TITLE:

\title{
ON THE OCCURRENCE OF ARCHIDISTOMA AGGREGATUM (A COLONY-FORMING ASCIDIAN) IN THE PACIFIC WATERS
}

\author{
$\operatorname{AUTHOR}(\mathrm{S})$ :
}

Nakauchi, Mitsuaki

\section{CITATION:}

Nakauchi, Mitsuaki. ON THE OCCURRENCE OF ARCHIDISTOMA AGGREGATUM (A COLONYFORMING ASCIDIAN) IN THE PACIFIC WATERS. PUBLICATIONS OF THE SETO MARINE BIOLOGICAL LABORATORY 1960, 8(2): 445-450

ISSUE DATE:

1960-12-20

URL:

http://hdl.handle.net/2433/174643

RIGHT: 


\title{
ON THE OCCURRENCE OF ARCHIDISTOMA AGGREGATUM (A COLONY-FORMING ASCIDIAN) IN THE PACIFIC WATERS ${ }^{1,2)}$
}

\author{
Mitsuaki NAKAUCHI ${ }^{3)}$ \\ Zoological Institute, Tokyo Kyoiku University
}

On June 26, 1957, in Nabeta Bay, on the coast of which the Shimoda Marine Biological Station is situated, a small colony of an ascidian was found. It was found attached to a glass plate floated on the sea for the purpose of rearing other ascidians. Thereafter the colony was reared in a culture box set out in the bay, and some observations were made on it.

This ascidian was identified as Archidistoma aggregatum by Dr. Takasi TokiokA of the Seto Marine Biological Laboratory. Furthermore, Dr. N. J. BerRILL, who has examined the material sent from the author, stated in his letter to the author: "I believe it is a species of Archidistoma, so far as I can tell, it appears to be same as $A$. aggregatum as found in the England Channel and Southeastern United States", supporting the identification by Dr. T. TокіокA.

In the summer of 1958, a considerable number of colonies belonging to the same species were collected in the vicinity of the Station, at the level of the low-tide mark. ${ }^{4)}$

Archidistoma aggregatum has been known as one of the most inconspicuous ascidians. It was recorded for the first time from Plymouth by Garstang in 1891, and for half a century it had been found only in the original locality and the near coast. In 1945, however, it was reported by VAN NAME that this ascidian had been found by BERrill in quantity at Beaufort, North Carolina, suggesting a wide distribution of this form. But no report has ever appeared on the occurrence of this species in Pacific waters, so, this is the first record of our form from that region.

All descriptions are based on living materials.

The details of the process of budding will be presented in a later paper.

1) Contributions from the Shimoda Marine Biological Station, No. 116.

2) Partly presented at the annual meeting of the Zoological Society of Japan, Matsuyama, October 1958.

3) Present address; Takaoka Kôtôgakkô, Kôchi, and Biological Institute, Kôchi Women's University.

4) The author is much indebted to Miss Reiko MANo of Zoological Institute of Tokyo Kyoiku University for her assistance in collecting the material.

Publ. Seto Mar. Biol. Lab., VIII (2), 1960. (Article 28) 
The author wishes to express his sincere gratitude to Professor Hidemiti OKA, under whom all the studies have been carried out, for his kind advice and guidance, further to all the persons of the Shimoda Marine Biological Station, especially Dr. Isokiti Harada, and Mr. Hiroshi Watanabe of Tokyo Kyoiku Univ. for their kind advice and help in various ways. The author is also much indebted to Dr. Takasi TokiokA of the Seto Marine Biological Laboratory for his constant guidance and encouragement and also for making possible the publication of this report, and to Dr. N. J. BERrILL, Professor of McGill Univ. of Canada, for his helpful suggestions and kind sending of valuable papers.

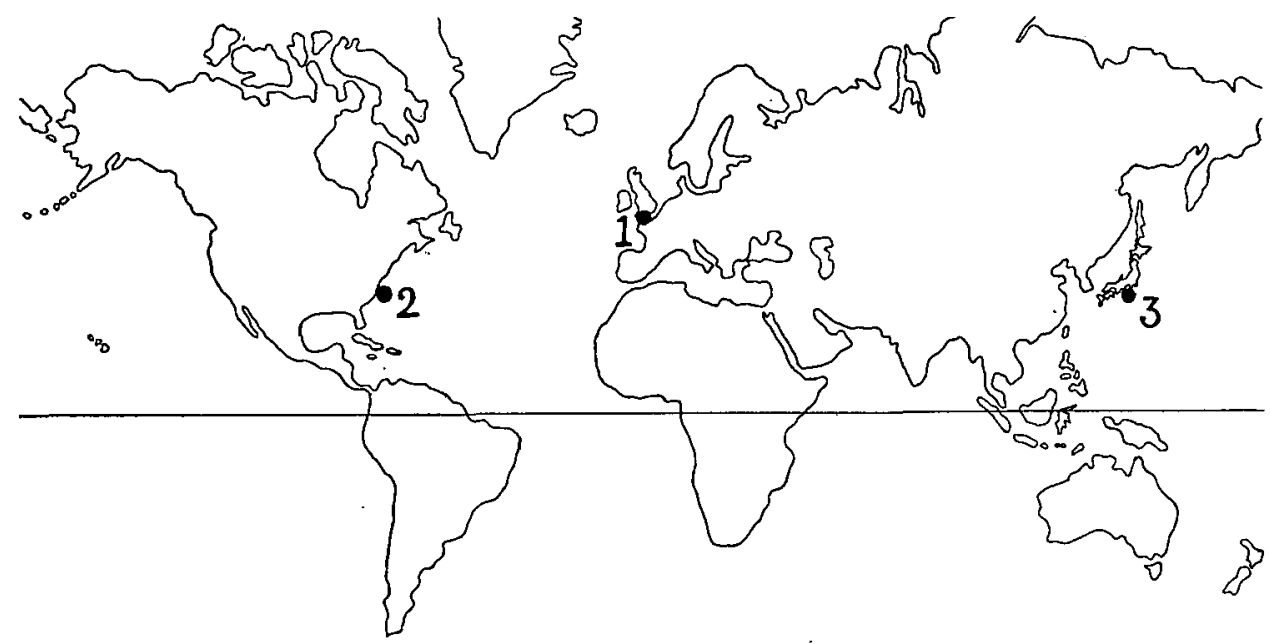

Fig. 1. Distribution of Archidistoma aggregatum.

1, Plymouth ; 2, Beaufort; 3, Shimoda.

\section{Colony}

The colony is rather massive, and consists of a semi-transparent gelatinous matrix with about ten zooids. The upper parts of some zooids project to a certain extent from the basal test, but some zooids are completely embedded in the common test. Some colonies are divisible into two or three clumps of zooids. The colony is colorless when the zooids are full-stretched, but it looks milky white when the zooids are contracted. Colonies are from 7 to $10 \mathrm{~mm}$ in width, and from 4 to $5 \mathrm{~mm}$ in height. Their surface is free from incrustations, but the test contains some feces pellets.

It is found attached to the under-surface of stones, and in many cases to the innerside of crevices, at the level of the spring low-tide.

In the natural habitat the zooids are located perpendicularly to the substratum on which they grow, the colony being massive as was mentioned above (Fig. $2 \mathrm{~A}$ ). But, when the colony is attached to a glass plate, the zooids sooner or later assume 
a different orientation, i.e., they come to lie with their ventral side directed towards the substratum, and the shape of the colony changes from massive to flat (Fig. 2 B).

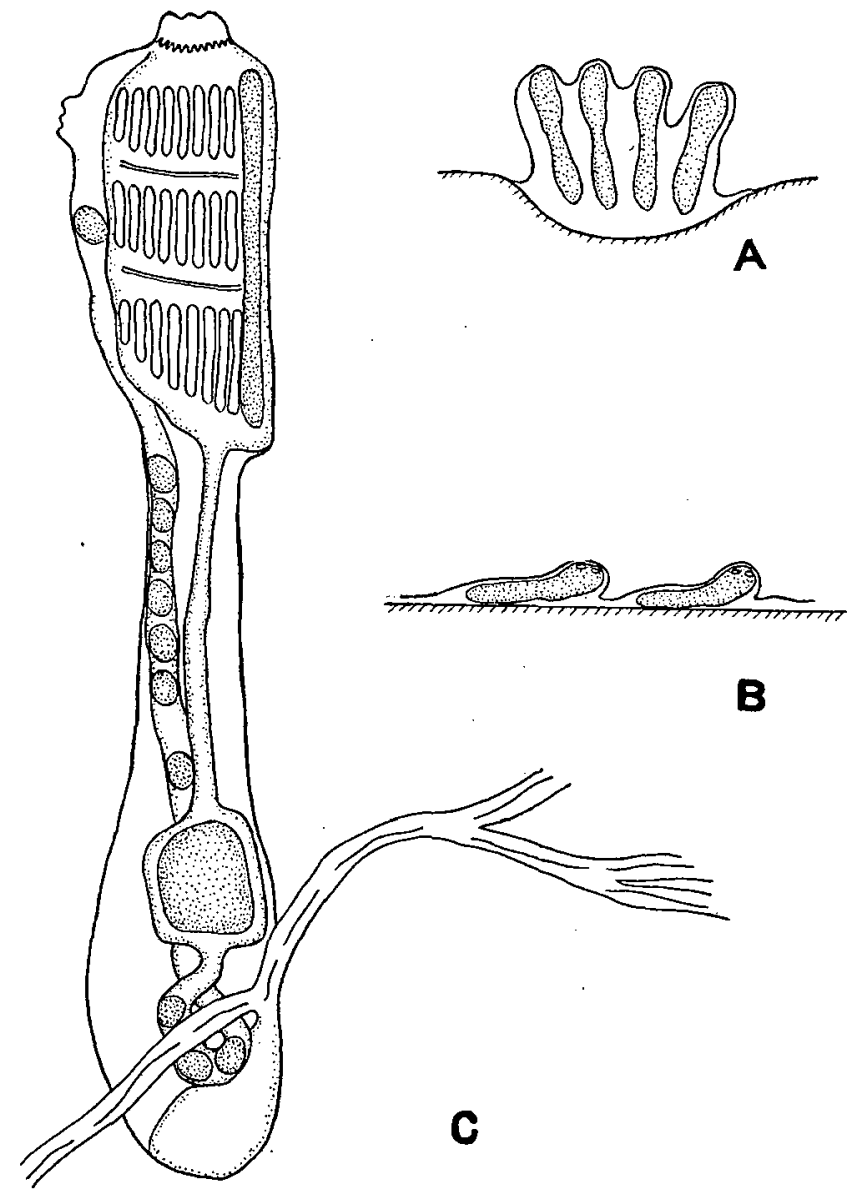

Fig. 2. Archidistoma aggregatum GARSTANG.

A, Colony growing on a stone, semi-diagramatic, $\times 5$.

$\mathrm{B}$, Part of colony growing a glass plate, semi-diagramatic, $\times 5$.

$C$, Zooid from right side, $\times 40$.

\section{Zooid}

The zooid shows a typical merosomatous form, not longer than $4 \mathrm{~mm}$ in length. The thorax is rather "slender", its length being about two-fifths of the total length of the zooid. But the thorax contracts to one-third in length when the zooid is stimulated or kept in an adverse condition. Two apertures are independent and six-lobed. There are three rows of gill slits, with 8 to 10 stigmata in each row. The abdomen is slender, too. The oesophagus is narrow and very long. 
The stomach is globular and smooth-walled, being orange-colored in life. In some zooids, the stomach wall has longitudinal orange stripes which are considered to be no true folds. Under the stomach the descending and ascending digestive tubes do not show a U shape, but make a perfect loop, crossing each other. The rectum is narrow and long, having many feces pellets. The heart lies horizontally at the base of the abdomen, just below the bend of the gut-loop. The long test vessels project from near the ventral (endostyle-side) end of the heart, branching

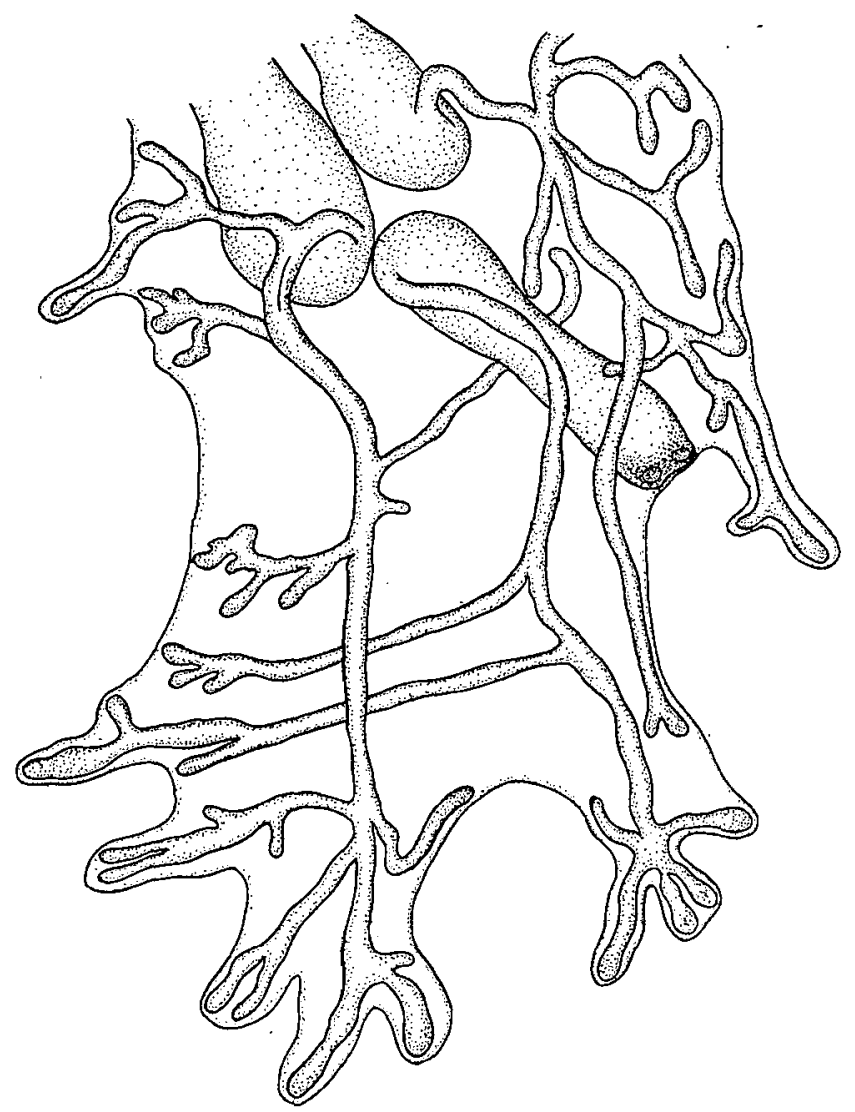

Fig. 3. Part of colony growing on a glass plate, showing three zooids and their long test vessels, ventral view. $\times$ about 10 .

throughout the test terminating at the edge of the test (Fig. 3). They are divided into two lumina by a septum. The septum is discontinuous, so two lumina anastomose intermittently, efferent and afferent blood being mixed in such parts. The epicardium lies at the ventral side of the digestive canal. In some zooids, the epicardium is milky white and recognizable through the test. It is very difficult in this form to observe the gonads in living material, so the details of them will be shown after histological observations are made. 
Some zooids contain large orange corpuscles in considerable numbers. They are seen in various parts of zooids, and sometimes they move slowly with blood, frequently aggregating to form masses of irregular shape.

\section{Remarks}

(a) On the distribution of our species

On the wide separation of two localities of this form, Plymouth and Beaufort, BERRILL ('50) points to two possibilities. One is that this form may be much more widely distributed than has been reported, because this form is possibly the most inconspicuous of all ascidians. The other is that this ascidian may have been transported by ships.

Shimoda is one of the oldest port in Japan, so, if the locality of this form in Japan is restricted to Shimoda or such ports, we shall be led to the conclusion that the latter possibility given by BERRILL is the case. However, our knowledge of Japanese ascidian fauna is so poor, that the author wishes to pass no opinion on this problem in the present paper.

(b) On the supernumerary heart

During the observation of living materials in 1957, or more exactly, on June 18 of that year, a zooid which possesses two hearts in a single abdomen' was found.

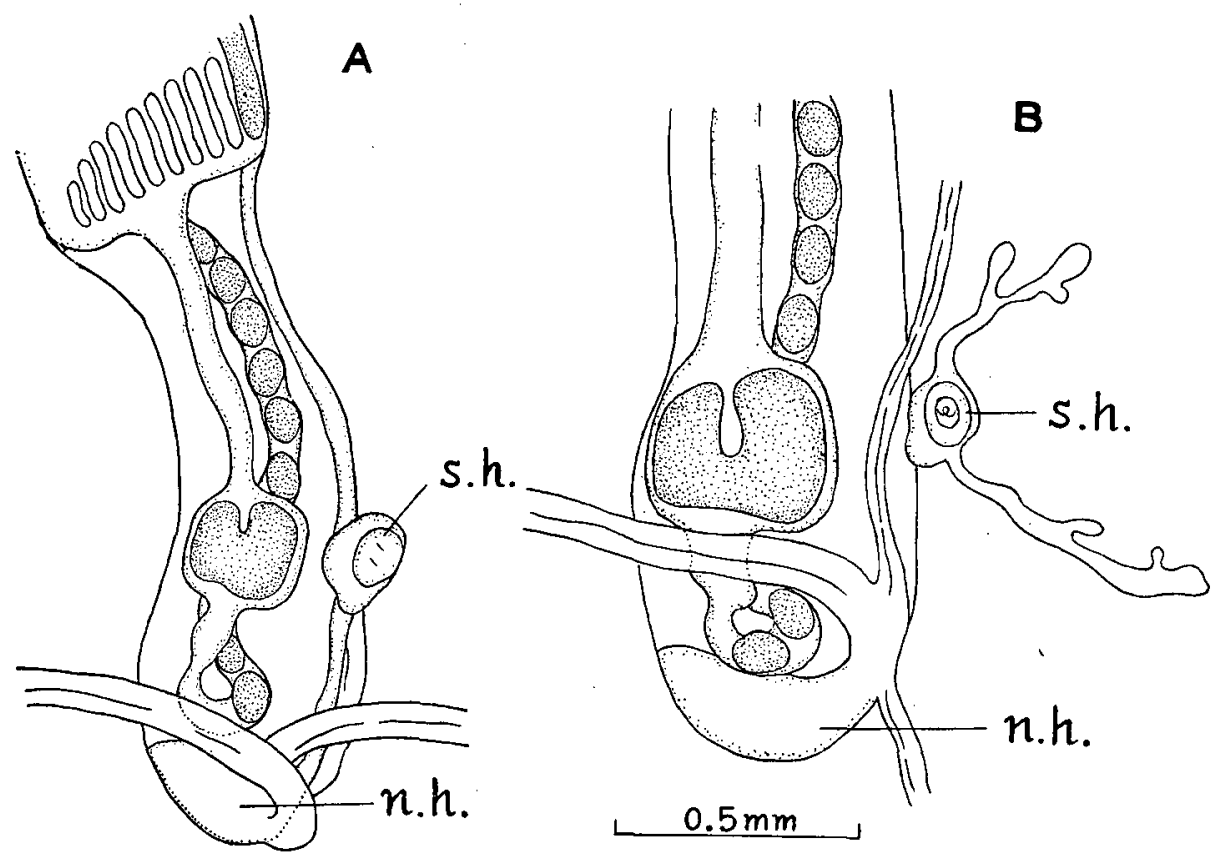

Fig. 4. Abdomen of zooid having a supernumerary heart, ventral view. n.h., normal heart; s.h., supernumerary heart.

A. 18. VII. ' 57 .

B. 3. VIII. '57. 
The zooid was about $2.5 \mathrm{~mm}$ in length and 11 days old - it was an blastozooid which had been arisen from a thoracic bud on June 7 .

The supernumerary heart was situated on the left ventral side of the abdomen, at the level of the stomach, and was a little smaller than the proper heart (Fig. $4 \mathrm{~A}$ ). There seemed to be no communication between two hearts, and the supernumerary one had normal heart beat, beating independently of the proper one.

About ten days after the heart had been found, two test vessels arose from the heart; they grew day by day, reaching their maximum size on August 3 (Fig. $4 \mathrm{~B}$ ), followed by degeneration. The heart beat was observed until August 4 , in other words, the heart functioned for 18 days.

The details of the observations will be published in another paper, in which the mechanism of the formation of supernumerary heart wil also be discussed.

So far as the author knows, there are no papers on ascidians which have two or more hearts; furthermore, there is no literature reporting the formation of such an ascidian by experimental methods. However, during the experiments on the regeneration in Polycitor mutabilis, a compound ascidian, the author had the oppotunity to observe ascidians which have two hearts in a single abdomen. Such hearts have been observed in natural (non-operated) as well as operated zooids. It seems, therefore, that the malformation of this type will be found in some other ascidians with the advance of research.

(c) Comparison between Atlantic and Pacific forms.

Unfortunately, the author has had no opportunity of studying materials from Atlantic waters. In the present comparison, therefore, descriptions given by Garstang ('91), Van Name ('45), and Berrill ('48, '50) have been used.

The Japanese form differs from the European (and American) form in the following points.

1) The colonies are more massive than those from Atlantic, i.e, the zooids are embedded for almost their whole length in the common test.

2) The thorax of Japanese form is more slender than that of European form.

3) The color of colonies is milky white (or colorless) in life, the Atlantic form being greenish olive or dark brown.

4) The zooids from Pacific waters are smaller than those from Atlantic waters.

5) The test vessels are very long in Japanese form.

\section{LITERATURE CITED}

Berrill, N. J. (1948): Structure, tadpole and bud formation in the ascidian Archidistoma. Jour. Mar. Biol. Assoc. U. K., Vol. 27, pp. 380-388.

(1950): The Tunicata with an account of the British Species. London.

Garstang, W. (1891): Note on a new and primitive type of compound ascidian. Zool. Anz., Bd. 14, pp. 422-424.

Nakauchi, M. (1959): Budding in Archidistoma aggregatum, a compound ascidian new to the Pacific Ocean. Zool. Mag. (Tokyo), Vol. 68, p. 142 (In Japanese).

Van Name, W. G. (1945): The North and South American ascidians. Bull. Amer. Mus. Nat. Hist., Vol. 84, pp. 1-476. 